P0153

\title{
COMFORT SUBJECTIVE EVALUATION OF DIFFERENT READING MEDIUM UNDER THE ILLUMINATION ENVIRONMENT IN LIBRARY READING ROOM \\ Wu Tongyao et al.
}

DOI 10.25039/x46.2019.PO153

from

CIE x046:2019

Proceedings

of the

29th CIE SESSION

Washington D.C., USA, June 14 - 22, 2019

(DOI 10.25039/x46.2019)

The paper has been presented at the 29th CIE Session, Washington D.C., USA, June 14-22, 2019. It has not been peer-reviewed by CIE.

(c) CIE 2019

All rights reserved. Unless otherwise specified, no part of this publication may be reproduced or utilized in any form or by any means, electronic or mechanical, including photocopying and microfilm, without permission in writing from CIE Central Bureau at the address below. Any mention of organizations or products does not imply endorsement by the CIE.

This paper is made available open access for individual use. However, in all other cases all rights are reserved unless explicit permission is sought from and given by the CIE.

CIE Central Bureau

Babenbergerstrasse 9

A-1010 Vienna

Austria

Tel.: +4317143187

e-mail: ciecb@cie.co.at

www.cie.co.at 


\title{
COMFORT SUBJECTIVE EVALUATION OF DIFFERENT READING MEDIUM UNDER THE ILLUMINATION ENVIRONMENT IN LIBRARY READING ROOM
}

\author{
Wu, Tongyao ${ }^{1}$, Wang, Lixiong ${ }^{1}$, Yu, Juan ${ }^{1}$, Zhang, Jingyi ${ }^{1}$ \\ Tianjin University, Tianjin, CHINA \\ 493424676@qq.com
}

DOI 10.25039/x46.2019.PO153

\begin{abstract}
Based on the visual comfort requirements of VDT reading and paper reading, the subjective evaluation experiment of the lighting environment in the library reading room in the laboratory is carried out. The experimental results show the importance coefficient of influence law and influencing factors of the visual comfort of laptop, mobile phones, paper books. The comfortable horizontal illuminance range of VDT reading is $200 \sim 300 \mathrm{~lx}$, the comfortable horizontal illuminance range of paper books reading is 500 750lx; 4000k-5000k is the common comfort colour temperature range for VDT and paper books reading; the black tabletop with lower reflectance is beneficial to improve both the comfort of VDT reading and paper reading; the luminance of reading background has the greatest influence on reading comfort; the order of importance factors and coefficient: luminance of reading background (0.24), reading tools $(0.20)$, colour temperature $(0.20)$, lighting style $(0.15)$, illuminance $(0.13)$, reflectance of reading background (0.08); Compared with general lighting, mixed lighting makes the comfort of paper reading slightly improved, while that of VDT reading slightly decreased. Reading comfort of laptop is generally higher than that of mobile phone.
\end{abstract}

Keywords: Library, VDT reading, subjective evaluation, reading comfort(visual comfort)

\section{Introduction}

With the advancement of science and technology, VDT (Visual Display Terminal) devices, such as computers, mobile phones, and tablet computers, have gradually become important reading carriers. As an important place for reading and learning, library has also been influenced by a new way of reading, that is, VDT reading. The research on the lighting environment of reading room in library is based on VDT reading and traditional paper reading comfort. And it will be able to improve the library lighting quality effectively and increase reading efficiency. What' $s$ more, it will provide basis for library lighting design.

According to the survey data of 14 municipal libraries and university libraries in Beijing, Tianjin, Shanghai, Suzhou, Guangzhou, Shenzhen and other cities, the typical library reading room space is shown in Table 1, there are general lighting and mixed lighting in the general. And notebook computer, mobile phone, and paper books are the three major types of library reading carriers. ${ }^{[1-3]}$

Based on the visual comfort requirements of reading, this paper carries out the subjective evaluation experiment of the lighting environment in the library reading room in the laboratory. Under two lighting style----general lighting and mixed lighting, the notebook computer, mobile phone and paper books are used as reading carriers respectively to study on the influence of visual comfort on reading. And a series of lighting design elements include colour temperature of light source,work-plane(desktop) horizontal illuminance, background (desktop and baffle) luminance and reflectance and so on. And the important order and coefficient of the above factors are obtained through integrated learning XGBoost algorithm calculation and other methods. 
Table 1 - Typical library reading room space

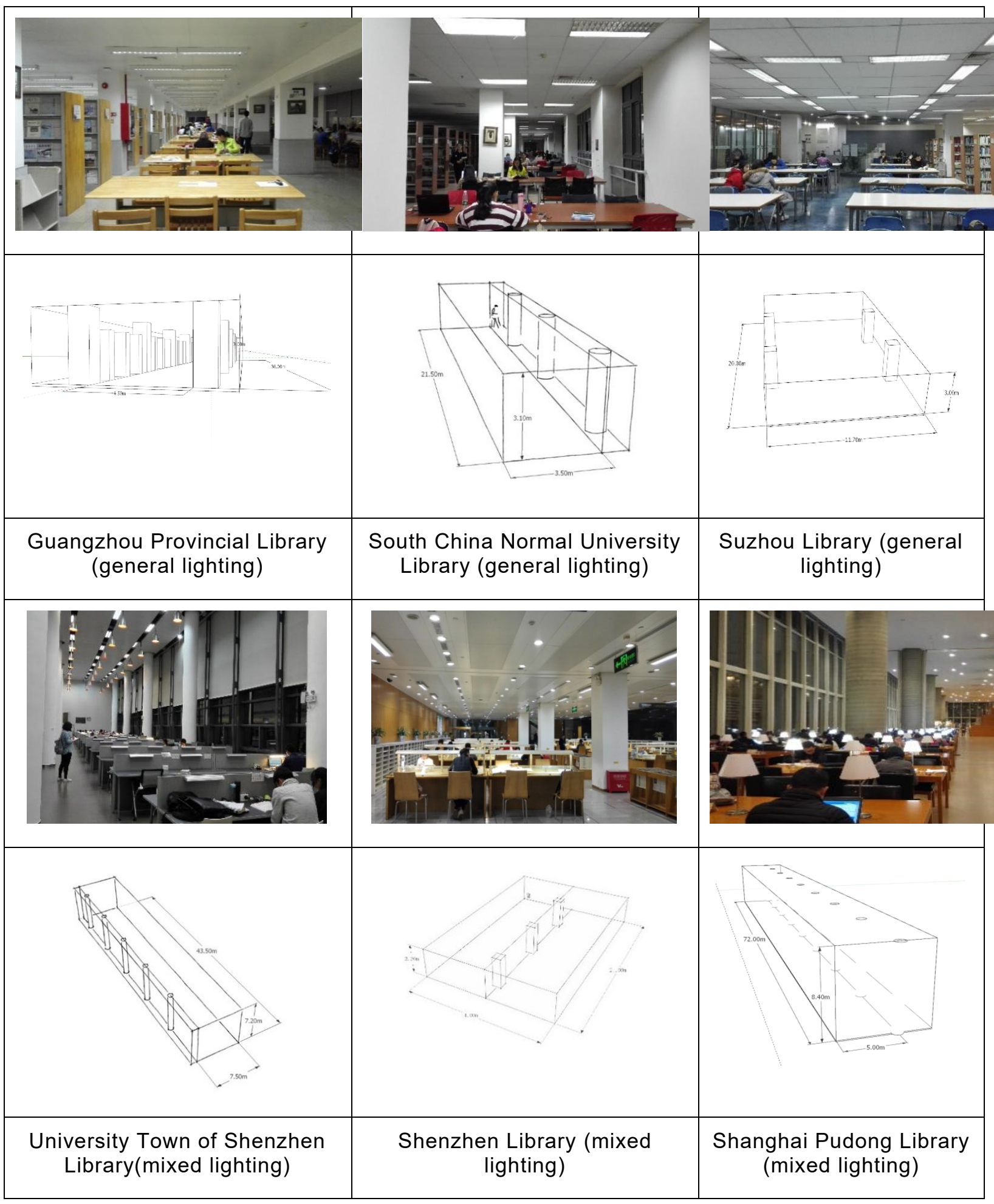

\section{Subjective Evaluation Experiment}

\subsection{The Experimental Variables}

According to the preliminary survey data and the current specification ${ }^{[4]}$, the experimental variables are set as shown in Table 2: the experiment of general lighting and mixed lighting is carried out at the same time; according to the different reflectance of the background (desktop and baffle), the experiment is divided into three groups: black, gray and white, which are carried 
out in random order. A total of 16 working conditions (4 levels of illumination * 4 levels of colour temperature) occur in random order in each group of experiments.

Table 2 - Subjective evaluation experimental variable settings

\begin{tabular}{|c|c|c|c|}
\hline category & parameters & Survey data & Experimental settings \\
\hline \multirow{5}{*}{ variables } & Lighting style & $\begin{array}{c}\text { General } \\
\text { lighting and } \\
\text { mixed lighting }\end{array}$ & General lighting and mixed lighting \\
\hline & $\begin{array}{l}\text { Reflectance of } \\
\text { reading } \\
\text { background }\end{array}$ & $0.09-0.63$ & $\begin{array}{l}\text { black, gray, white:The measured reflectance } \\
\text { are } 0.11,0.33 \text {, and } 0.76 \text {, respectively. }\end{array}$ \\
\hline & $\begin{array}{c}\text { Desktop } \\
\text { horizontal } \\
\text { illuminance }\end{array}$ & $\begin{array}{c}2001 x- \\
750 \mid x(2 / 3 \\
\text { illumination }\end{array}$ & 2001x, 3001x, 5001x, 750lx \\
\hline & $\begin{array}{c}\text { Reading } \\
\text { background } \\
\text { (desktop and } \\
\text { baffle) } \\
\text { luminance }\end{array}$ & 1 & $\begin{array}{c}\text { Black:5.00、7.17、12.14、16.52 } \\
\text { Grey:23.71、33.36、55.59,63.62 } \\
\text { White:76.58、87.95、145.10、198.10 } \\
\left(\mathrm{cd} / \mathrm{m}^{2}\right)\end{array}$ \\
\hline & $\begin{array}{c}\text { colour } \\
\text { temperature of } \\
\text { light source }\end{array}$ & $2800 k-6300 k$ & $3000 \mathrm{k}, 4000 \mathrm{k}, 5000 \mathrm{k}, 6000 \mathrm{k}$ \\
\hline $\begin{array}{l}\text { Control } \\
\text { variable }\end{array}$ & $\begin{array}{c}\text { colour } \\
\text { rendering index } \\
\text { of light source }\end{array}$ & $70-86$ & 85 \\
\hline
\end{tabular}

\subsection{Experimental Space Setting}

Tianjin University has researched for five years and built the largest and most perfect light environment simulation laboratory in Asia. The experimental cabin covers an area of 800 feet and can be enclosed freely by light partition walls; the roof height of the " $6 \mathrm{~m}^{*} 6 \mathrm{~m}$ " roof can be adjusted in the range of $3 \mathrm{~m}-9 \mathrm{~m}$ through the roof lifting system; a total of 256 high-power LED lamps are installed on the roof, each of which can steplessly adjust the colour temperature, light flux and other indicators, and can simulate different artificial lighting environment.

Table1 lists some typical spaces selected from the research libraries. The experimental space is abstracted from the reading space of the typical library. The experimental space is constructed in the original proportion by using the experimental chamber. The results of the experimental space construction are shown in Figure 1.

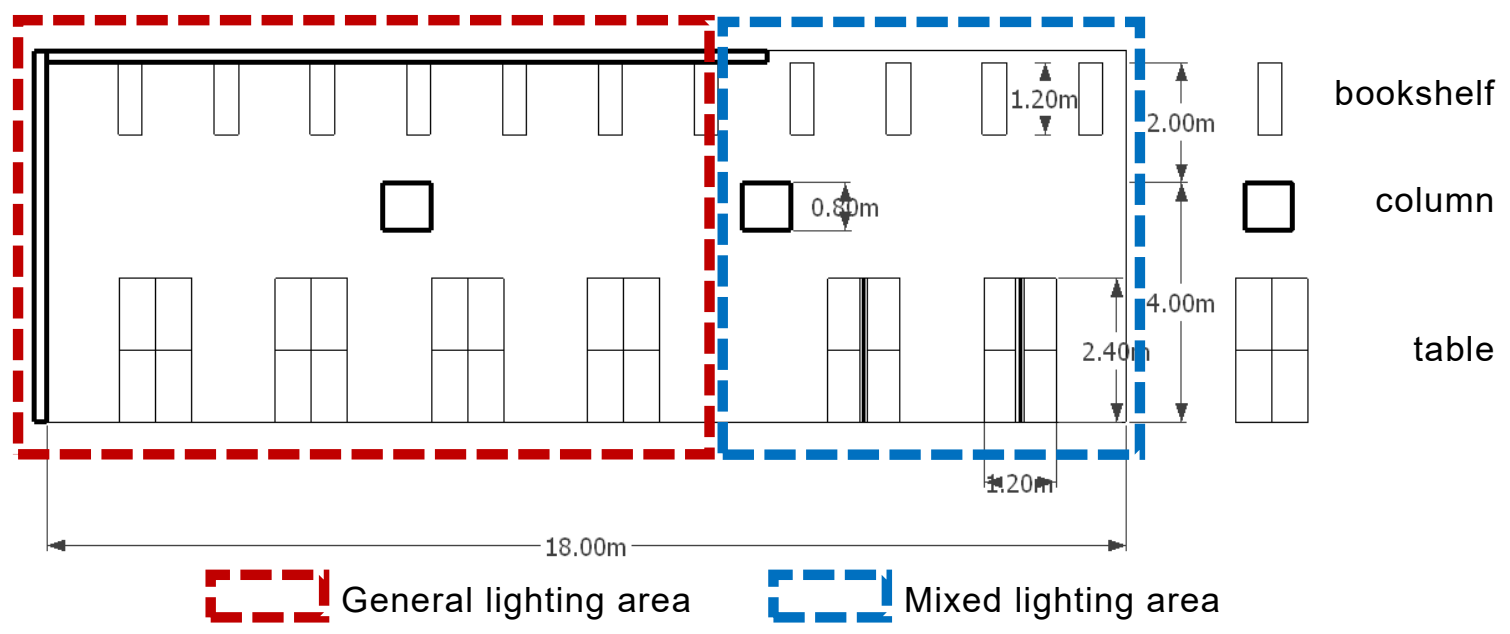




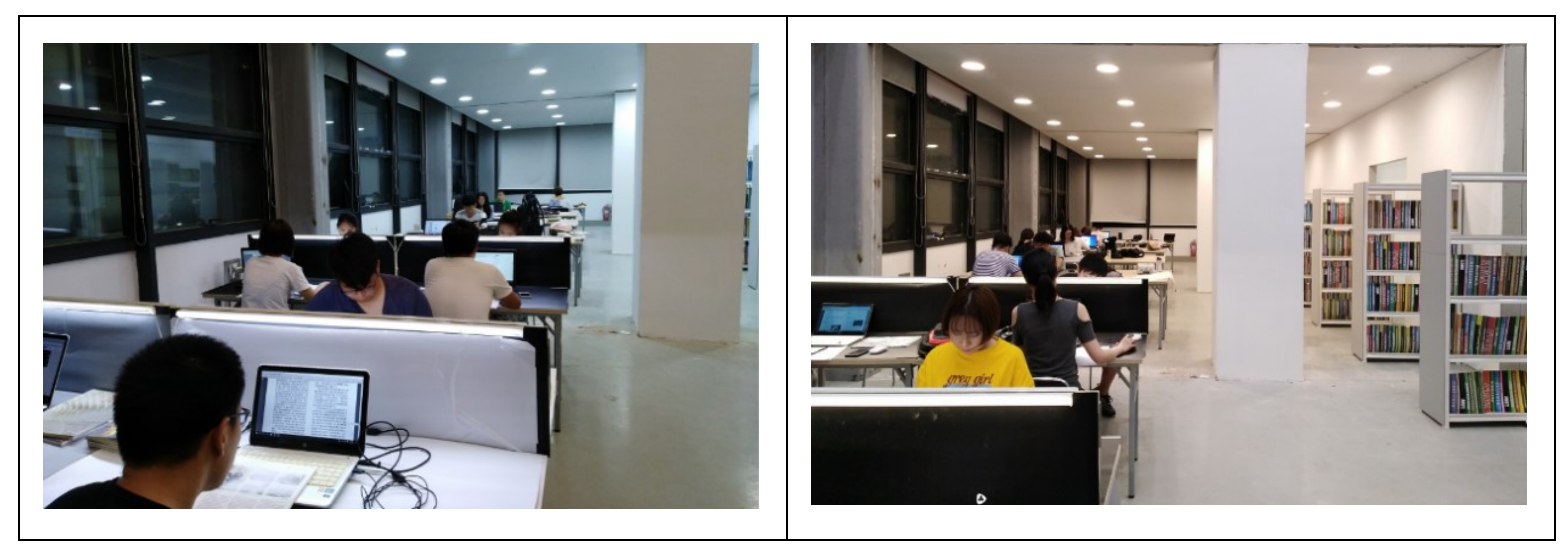

Figure 1 - Subjective Evaluation Experiment Site

\subsection{The Experimental Subjects}

A total of 76 ( 38 males and 38 females), ages between 18 and 45 . The subjects are all in good health with corrected visual acuity. They have no history of colour blindness, colour weakness or eye disease.

\subsection{The Experimental Procedure}

- The experimenter regulates screen luminance of cell phone: hang $100 \mathrm{~cd} / \mathrm{m}^{2}$ most appropriate luminance ${ }^{[2]}$.

- Eight participants participated in the experiment at the same time, and after freely visiting the library's general reading room space (space perception) restored by the laboratory, four subjects as a group sat in the general lighting area and the designated area of the mixed lighting area separately .

- The subjects wear eye patches, and the experimenter adjusts the spatial illumination source parameters and environmental parameters to the setting requirements of experimental variables set in working condition 1.

- After removing the eye patches, the subjects first adapt 30s light environment and then read through the phone. During the reading process, the subjects can zoom in or out the text according to their daily reading habits. And the reading content includes text and pictures.

- After reading for 1 minute, the subjects make subjective evaluation on the reading comfort of mobile phones under the current working condition and fill in the questionnaire.

- Under the same working condition, the subjects read paper books which cover text and pictures. After reading for 1 minute, the subjects make a subjective evaluation on the reading comfort of paper books under the current working condition and fill in the questionnaire.

- After the subjective evaluation experiment of the first working condition being completed, the subjects wear eye patches. And the experimenter adjusts the spatial illumination source parameters and environmental parameters to the setting requirements of the experimental variables set in working condition 2 . The above experimental steps are repeated to complete the experiment of all 16 working conditions successively.

- The subjects rest for 20 minutes. The subjects change the table liner to change the reflectance of the reading background surface. Repeat the above experimental steps and complete all 3 groups of experiments successively. That day' s experiment end.

- On the second day, the two groups of subjects exchange their positions and complete the evaluation experiment of another method of lighting style (all subjects complete three groups of experiments in general lighting environment and mixed lighting environment), and repeat the above experimental steps.

- The reading comfort experiment of laptop is the same as that of mobile phone 


\section{The Experimental Results}

According to the different factors considered in the previous experimental setup, the experimental results are analyzed in seven aspects: illuminance, colour temperature, reflectance of reading background, lighting style, luminance of reading background, and the influence of different reading tools on reading comfort. The experimental results are shown in Figures 2-7.
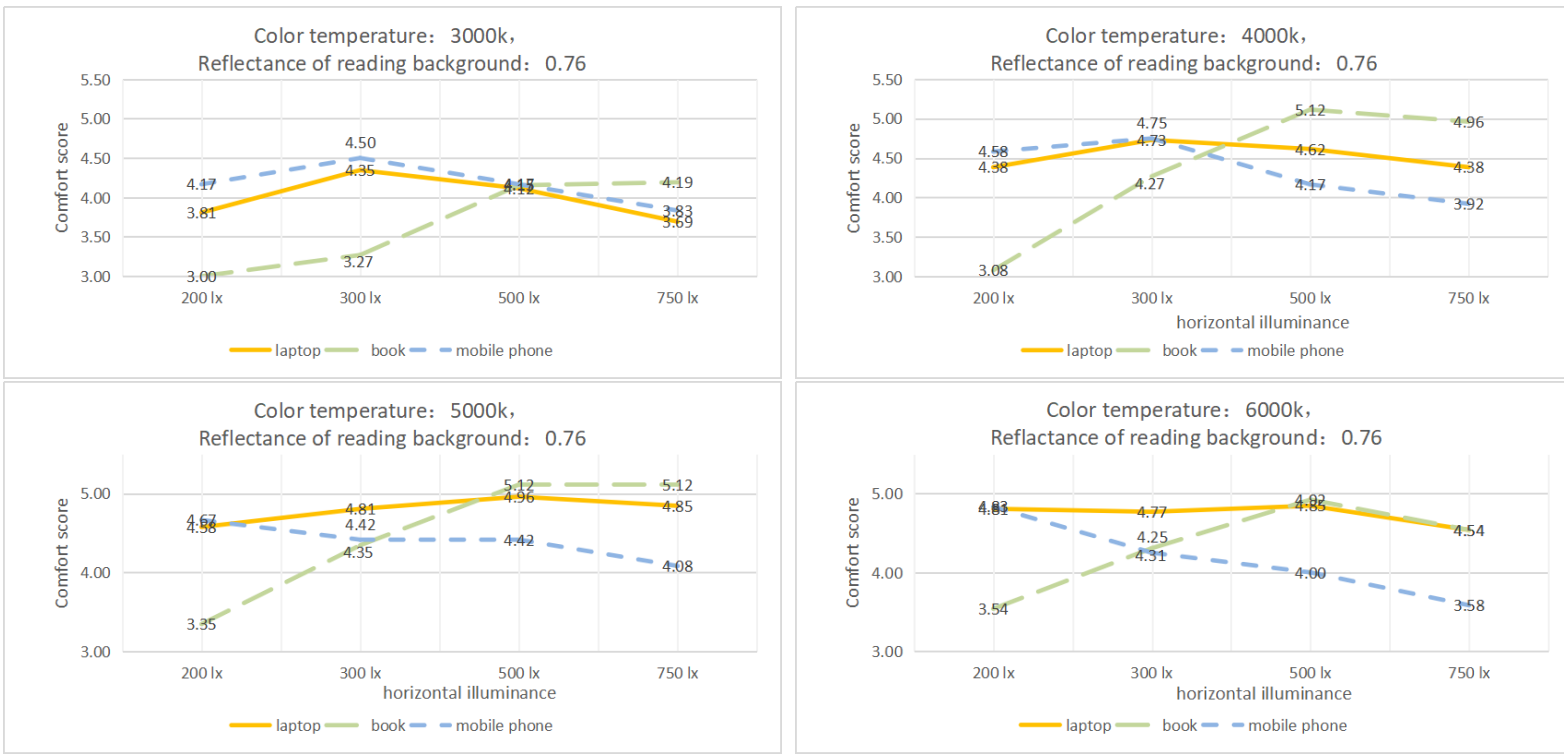

Figure 2 - Subjective evaluation experiment results (general illumination, reflectance of reading background $\mathbf{0 . 7 6 )}$
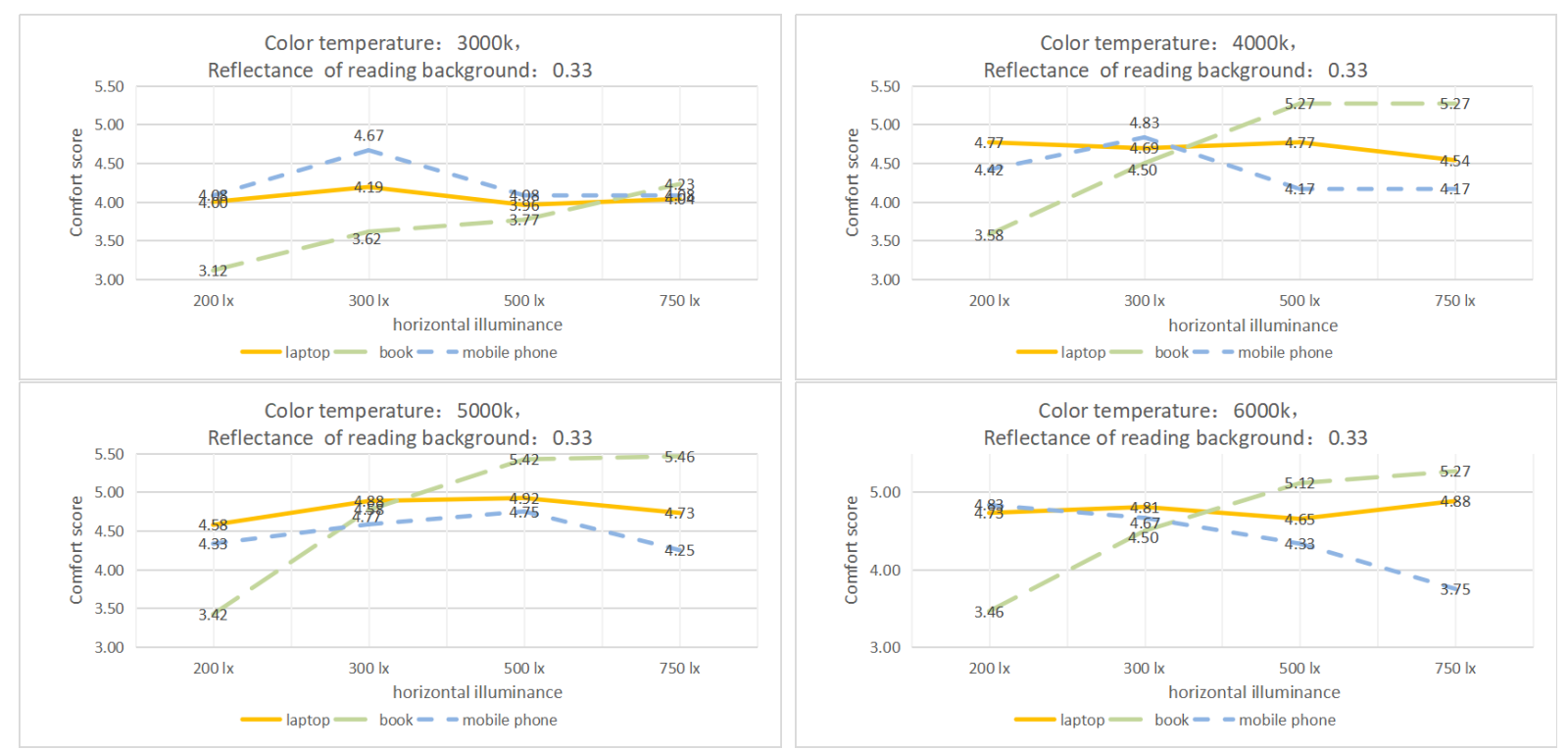

Figure 3 - Subjective evaluation experiment results (general illumination, reflectance of reading background 0.33 ) 

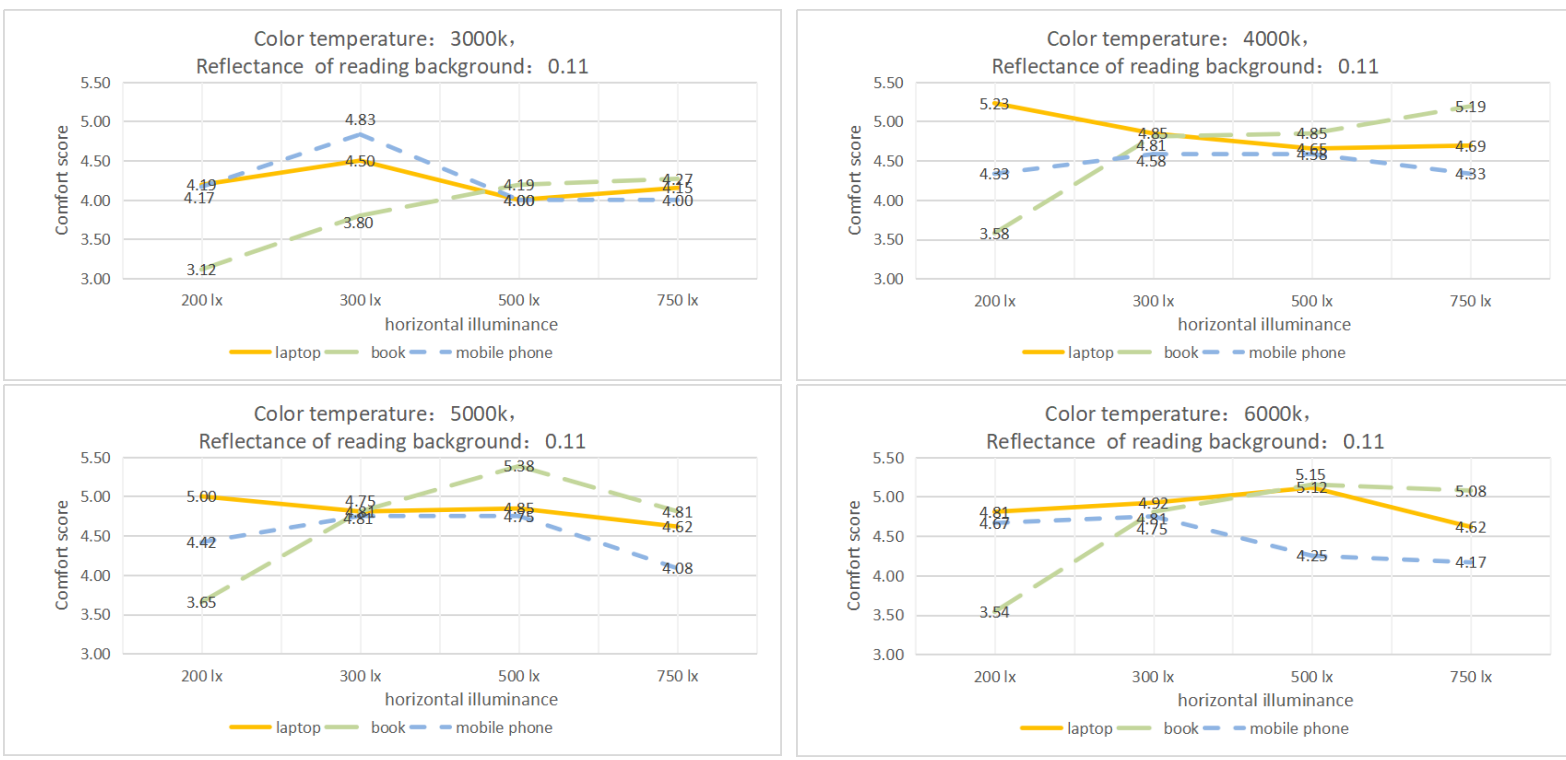

Figure 4 - Subjective evaluation experiment results (general illumination, reflectance of reading background $\mathbf{0 . 1 1}$ )
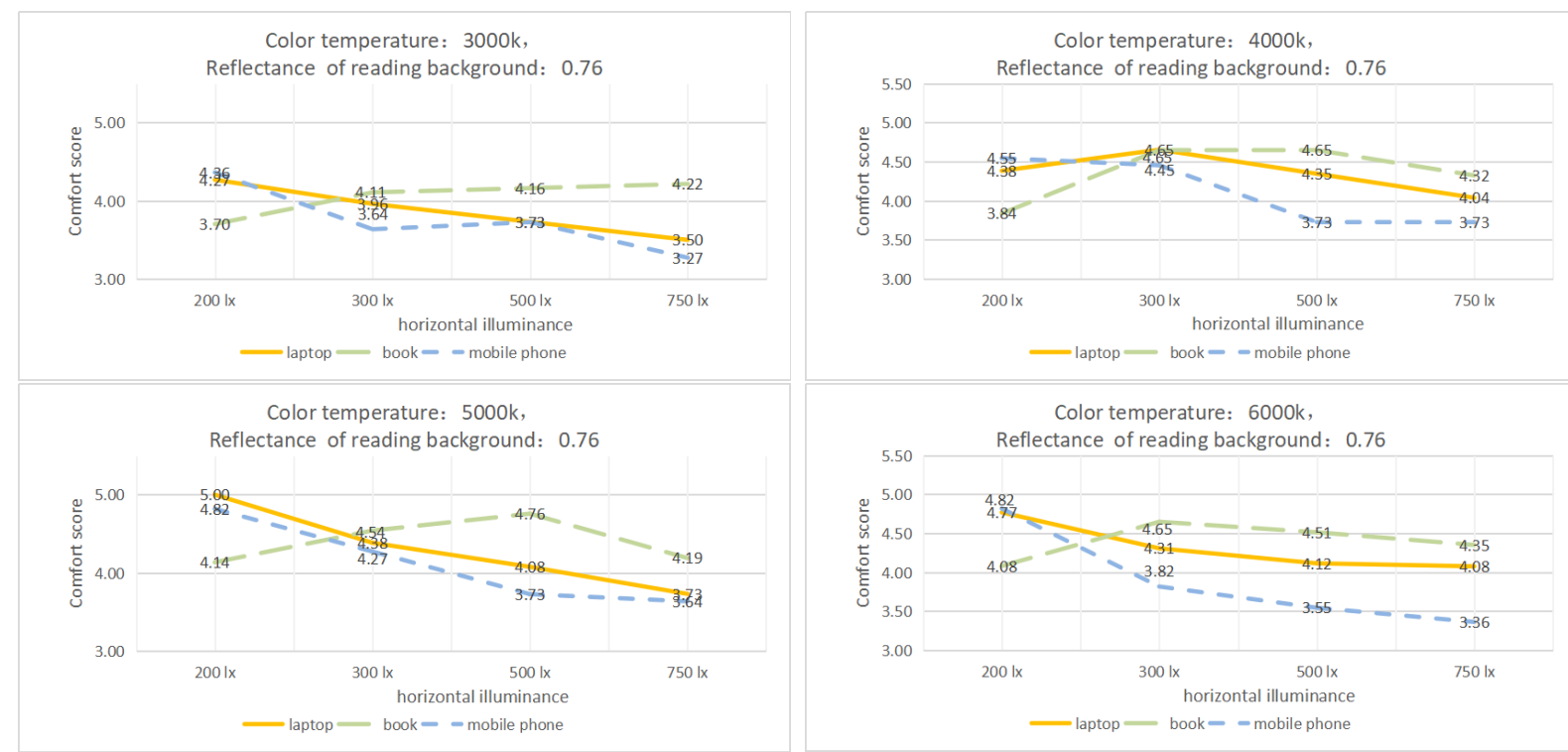

Figure 5 - Subjective evaluation experiment results (mixed illumination, reflectance of reading background 0.76 ) 

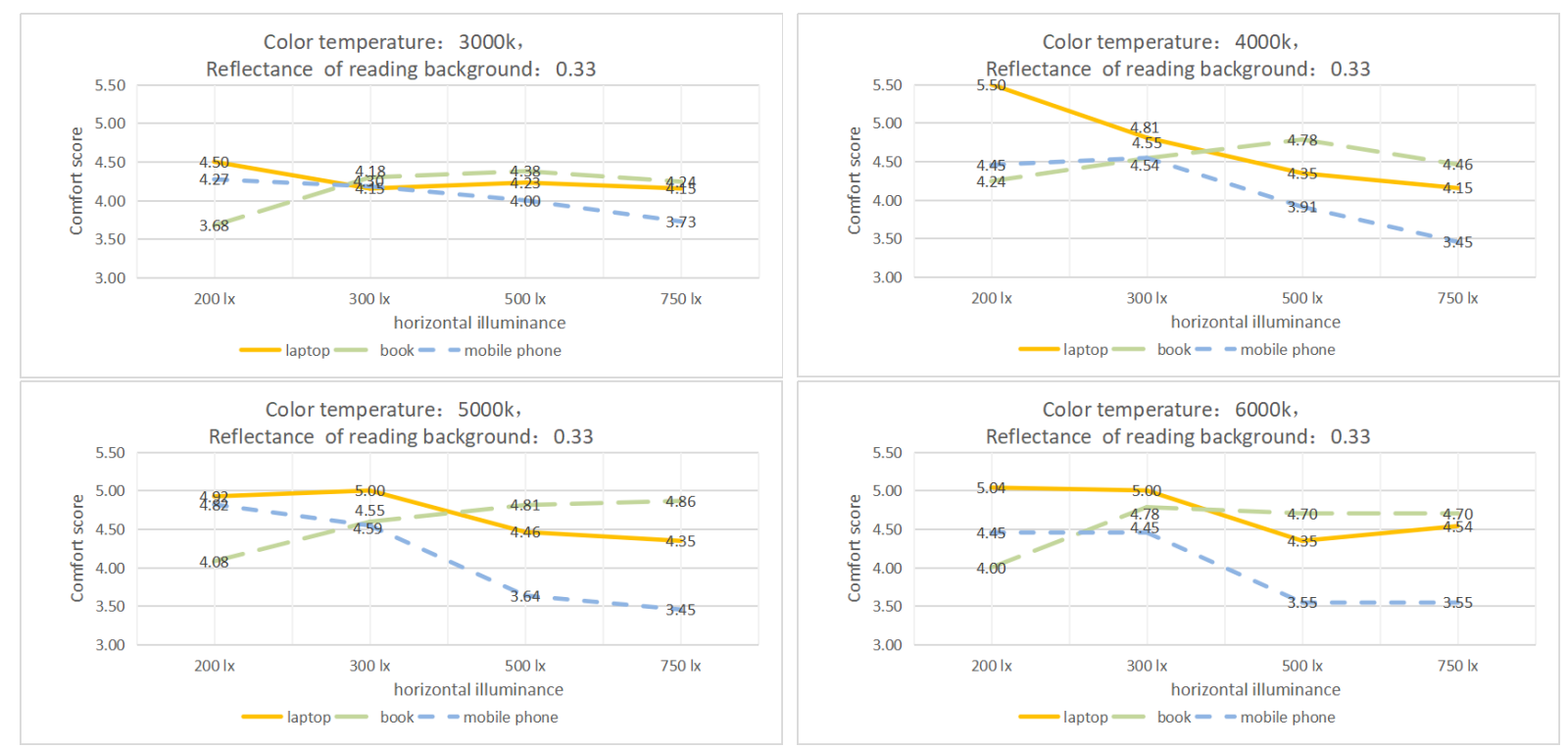

Figure 6 - Subjective evaluation experiment results (mixed illumination, reflectance of reading background 0.33 )
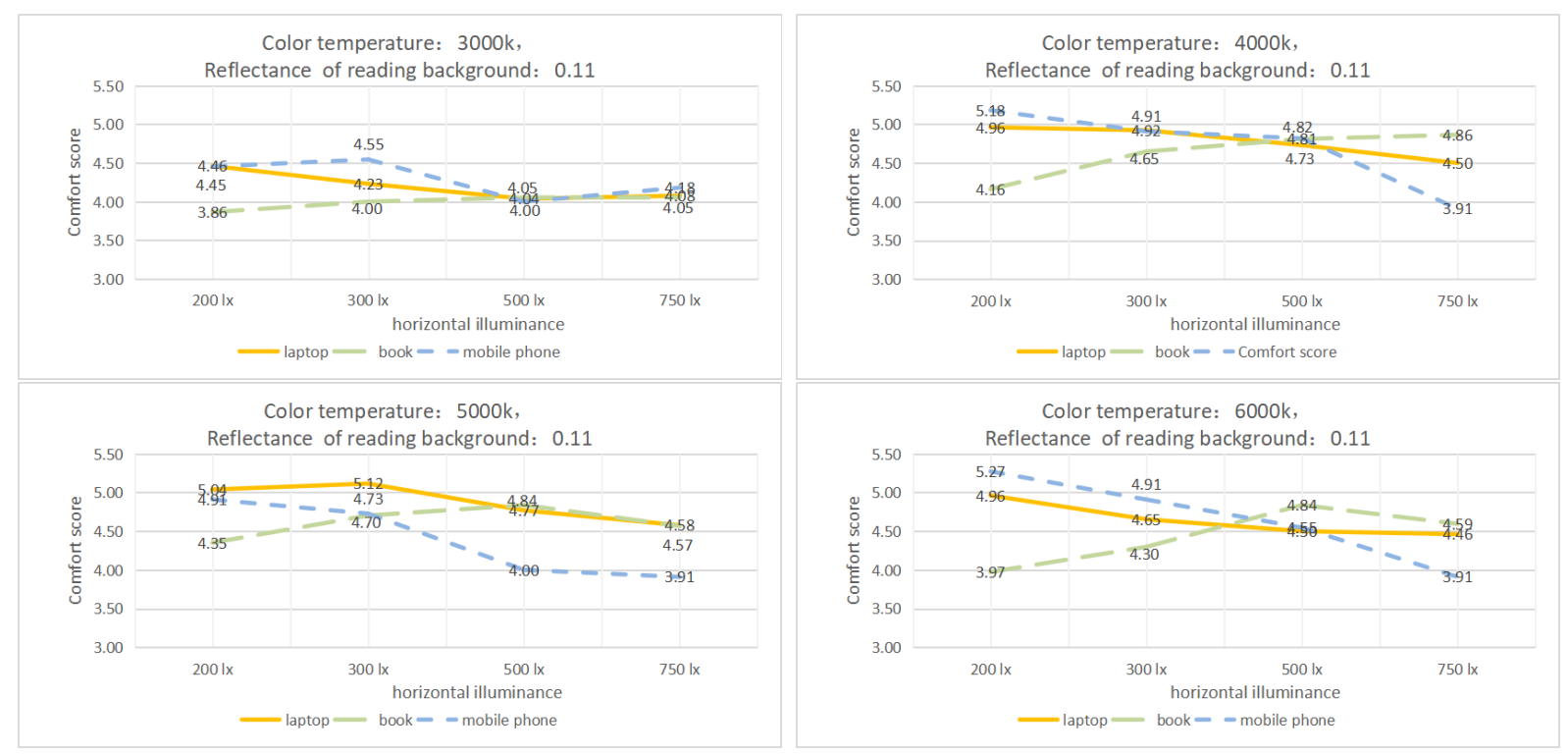

Figure 7 - Subjective evaluation experiment results (mixed illumination, reflectance of reading background 0.11)

Based on the experimental data, the library light comfort classification and evaluation model is established by using integrated learning XGBoost algorithm. The experimental data were randomly divided into training set and test set according to the ratio of $4: 1$ for calculation and analysis. The prediction accuracy of the generated model in the training set was 0.94 , and that in the test set was 0.79 . The order of importance of the elements from large to small and the corresponding importance coefficient are: luminance of reading background (0.24), reading tools (0.20), colour temperature of light source $(0.20)$, lighting style $(0.15)$, horizontal illuminance of desktop (0.13), reflectance of reading Background (0.08). 


\section{The Experimental Discussion}

Based on the experimental results shown in Figure 4-7, the discussion is as follows:

1 Lighting style:Compared with general lighting, the mixed lighting makes paper reading comfort slightly improved and VDT reading comfort slightly reduced;

2 Reading tools: Under the same working conditions, laptop reading comfort is generally higher than that of mobile phones;

3 The comfort range of reflectance of reading background:The lower black desktop is conducive to improving the comfort VDT reading and paper reading.

4 The comfort range of desktop illuminance:The comfortable illumination range of VDT reading is $200 \sim 3001 x$, and that of paper reading is $500 \sim 7501 x$.

5 The comfort range of the colour temperature of light source:4000k-5000k is a common comfort colour temperature range shared by VDT and paper reading.

6 The range of background luminance of reading surface:The background luminance of reading surface has the most significant influence on reading comfort.

\section{Conclusion}

Through the library research, subjective evaluation experiment, experimental data analysis, integrated learning XGBoost algorithm calculation and other methods, this paper analyzes the influence law of the reading comfort of using different reading tools in the library and the importance coefficient of the influencing factors. This paper can optimize the lighting design of the libraries in the new era and provide a more comfortable lighting environment for different ways of reading.

\section{References}

[1] Tongyao W.2019.Subjective evaluation of VDT reading comfort in Library lighting environment[D].Tianjin University

[2] Qi G.2018.Research on Lighting Environment of Library Reading Spaces Based on Different Reading Media [D].Tianjin University

[3] Tongyao W.et al.Wang Lixiong.Yu Juan. Quan Xiaoli. Mao Xikai.2018.Subjective evaluation of mobile phone reading comfort in artificial lighting environment.China Illuminating Engineering Journal,2018,12,29

[4] Standard for test and assessment of green lights GB/T 51268-2017 